\title{
Chemical characterization and enological potential of less frequent red grape Uruguayan varieties by study secondary metabolites
}

\author{
E. Boido ${ }^{1}$, L. Fariña ${ }^{1}$, C. Barnaba ${ }^{2}$, Y. Arrieta ${ }^{2}$, R. Larcher $^{2}$, G. Nicolini² ${ }^{2}$ F. Carrau ${ }^{1}$, and E. Dellacassa ${ }^{1}$ \\ ${ }^{1}$ Universidad de la Republica Uruguay, Facultad de Química, Gral. Flores 2124, 11800 Montevideo, Uruguay \\ ${ }^{2}$ Centro Trasferimento Tecnologico, Fondazione E. Mach, via E. Mach 1, 38010 San Michele all'Adige (TN), Italia
}

\begin{abstract}
Study of secondary grape metabolites, such as polyphenol compounds (anthocyanins, flavonols, flavan-3-ols), volatile compounds present in grapes in both free and glycoside forms (monoterpenols, norisoprenoids, benzenoids), allowed us to characterize grape varieties and to suggest the best winemaking practices to maximize their enological potential. The Vitis viniferas studied in the present work are less frequent red grape varieties cultivated in small vineyards in southern Uruguay (Montevideo and Canelones Provinces): Ancellota, Aspiran Bouschet (syn. Lacryma Christi), Marselan (Grenache $\times$ Cabernet Sauvignon), Arinarnoa (Tannat $\times$ Cabernet Sauvignon), Egiodola (Abouriou $\times$ Tinta Negra Mole) and Caladoc (Malbec $\times$ Grenache).
\end{abstract}

\section{Introduction}

The grapevine (Vitis vinifera), belonging to the Vitaceae family, comprises species actually distributed in almost all the continents, usually under subtropical, Mediterranean and continental-temperate climatic conditions. The great majority of cultivars widely cultivated for wine, classified as Vitis vinifera L. spp vinifera, derive from wild forms (This et al., 2006).

However, and for different reasons (mainly pathogenic problems and climate conditions), the main cultivars used for grape production on a worldwide basis are changing rapidly.

Uruguay currently has almost 6,500 hectares (http: // www.inavi.com.uy/uploads/archivos/Estadisticas de_Vinedos_Nacionales_2017.pdf) of vineyards, being fundamentally a country of small producers where $100 \%$ of the establishments have been family properties for more than three generations.

Among the Uruguayan wines, those elaborated from Vitis vinifera $\mathrm{cv}$ Tannat are the most known, being this varietal representative of the country wines between international consumer. Nevertheless, work is being carried out to improve quality to obtain premium wines, through blends using less frequent grape varieties being introduced and employed in the wine production looking for sensory particularities.

The aim of this study was to determine, by means of HPLC-DAD and HPLC-MS (Orbitrap), the polyphenolic profiles of six red Vitis vinifera L. grape varieties cultivated in small vineyards in southern Uruguay (Montevideo and Canelones Provinces) in the 2016 vintage. The selected varieties were: Ancellota, Aspiran Bouschet (in Uruguay syn. Lacryma Christi), Marselan (Grenache $\times$ Cabernet Sauvignon), Arinarnoa (Tannat $\times$ Cabernet Sauvignon),
Egiodola (Abouriou $\times$ Tinta Negra Mole) and Caladoc (Malbec $\times$ Grenache).

\section{Materials and methods}

\subsection{Grape samples and polyphenolic compounds extraction}

This study considered 6 red grape varieties (Vitis vinifera L.) cultivated in small vineyards in southern Uruguay in the 2016 vintage. The selected varieties were: 4 varieties obtained by crossing (Marselan, Arinarnoa, Egiodola and Caladoc), the Ancellota variety and a Tintorera cultivar (Aspiran Bouschet, in Uruguay syn. Lacryma Christi). Marselan is a crossing between Grenache and Cabernet Sauvignon; the Arinarnoa between Tannat and Cabernet Sauvignon; the Egiodola crossing between Abouriou and Tinta negra Mole; and Caladoc between Malbec and Grenache.

Marselan grapes were sampled from Las Brujas (Canelones Province) and Las Violetas (Canelones) while Arinarnoa samples were collected in Las Violetas (Canelones) and Montevideo Province. Egiodola grapes were collected from Suárez (Canelones), Ancellota from Sauce (Canelones) and Aspiran Bouschet and Caladoc from Juanicó (Canelones).

In order to extract anthocyanins and polyphenols compounds, forty grape berries were weighted, the seeds and skins were separated manually, and pulps were discarded (García-Marino et al., 2006; Boido et al., 2011).

\subsection{Polyphenolic compounds analysis}

\subsubsection{Targeted analysis (HPLC-DAD)}

The targeted analysis aimed at the identification and quantification of anthocyanins in skin extracts. It was 
Table 1. Aromatic precursors concentration $(\mu \mathrm{g} / \mathrm{kg})$ in the different varieties.

\begin{tabular}{|l|c|c|c|c|c|c|}
\hline & Arinarnoa & Marselan & Ancellota & Caladoc & Egiodola & Aspiran B. \\
\hline C6 compounds & 125 & 93 & 225 & 139 & 104 & 149 \\
\hline terpenes & 68 & 44 & 131 & 62 & 57 & 124 \\
\hline C13-norisoprenoids & 429 & 149 & 231 & 156 & 204 & 86 \\
\hline benzenoids & 270 & 167 & 353 & 145 & 240 & 428 \\
\hline volatile phenols & 510 & 579 & 410 & 354 & 352 & 448 \\
\hline
\end{tabular}

performed with an Agilent 1200 Series HPLC (Agilent Technologies, Santa Clara, CA, USA), using a Porospher ${ }^{\circledR}$ LiChroCart ${ }^{\circledR}$ RP18 $(250 \times 4 \mathrm{~mm}, 5 \mu \mathrm{m}$ particle size, Merck Group, Darmstadt, Germany) following the experimental conditions reported by Castia et al. (1992).

\subsubsection{Non-targeted analysis (HPLC-MS)}

The non-targeted analysis aimed at the tentative identification of free and bound phenols in both skin and seed extracts. The chromatographic separation was performed with a Thermo Ultimate ${ }^{\mathrm{TM}} 3000$ HPLC was coupled with a tandem mass spectrometer (Q-Exactive ${ }^{\mathrm{TM}}$; Thermo Scientific, Bremen, Germany) furnished with a heated electrospray source (HESI-II). The mass analysis was performed in negative ion mode, adapting the method proposed by Barnaba et al. (2017). LC column $(150 \mathrm{~mm} \times 3 \mathrm{~mm}, 2.6 \mu \mathrm{m}$ particle size; Thermo Fischer Scientific, Waltham, MA, USA) was used.

\subsection{Volatile compounds analysis}

The extraction of volatile compounds and aromatic precursors was carried out using an Isolute (IST Ldt., Mid Glamorgan, U.K.) ENV + cartridge packed with $1 \mathrm{~g}$ of highly cross-linked-styrene-divinyl benzene (SDVB) polymer. The extractions of free and glycosylated volatile compounds was carried out according to the procedure described by Boido et al. (2013). GC-MS analysis was performed on a GC-MS QP 2010, using a Stabilwax capillary column $(30 \mathrm{~m}, 0.25 \mathrm{~mm}, 0.25 \mu \mathrm{m}$ film thickness; Restek Corporation, Bellefonte, PA.) according to Boido et al. (2013).

\section{Results and discussion}

\subsection{Polyphenolic compounds}

\subsubsection{Targeted analysis}

The targeted approach made it possible to quantify 9 anthocyanidin derivatives, 5 of which were anthocyanins (delphinidin-3-glucoside, DP; cyanidin-3-glucoside, CN; petunidin-3-glucoside, PT; peonidin-3-glucoside, PN; malvidin-3-glucoside, MV), 4 acylated anthocyanins [delphinidin-3-(6" -acetylglucoside), ac-DP; petunidin-3(6"-acetylglucoside), ac-PT; peonidin-3-(6"-acetylglucoside), ac-PN; malvidin-3-(6"-acetylgalactoside)], ac-MV) and 4 coumarylated anthocyanins (delphinidin-3(pcoumglc), coum-DP; cyanidin-3-(pcoumglc), coum-CN; peonidin-3-(pcoumglc), coum-PN; malvidin-3-(pcoumglc), coum-MV)] allowing to define the skin characteristic profile for each variety.

\subsubsection{Non-targeted analysis}

The non-targeted approach allowed the detection of 66 phenolic compounds, of which 41 were tentatively identified in the form of hexose (32), deoxyhexose (7), hexose-pentose (1) and hexose-deoxyhexose (1), based on the neutral loss and the characteristic sugar ring fragmentations (Domon and Costello, 1988).

The compounds detected were classified as flavonols and their glycosylated derivatives (21), hydroxybenzoic acids and their glycosylated derivatives (11), hydroxycinnamic acids and their glycosylated derivatives (8), glycosylated flavanonols (7), flavan-3-ols and their glycosylated derivatives (5), alkylphenyl alcohols and their glycosylated derivatives (4), glycosylated simple phenol (1), glycosylated flavanones (2), hydroxybenzoketones and derivatives (2), hydroxybenzaldehyde (1), hydroxycoumarin (1), glycosylated hydroxyphenylacetic acid (1), glycosylated flavone (1) and glycosylated hydroxybenzylether (1).

\subsection{Volatile compounds}

The aromatic precursors concentration in the varieties analyzed is presented in Table 1. All the varieties present low concentration of terpenes compounds, with the high concentration in Ancellota and Aspriran Bouschet. On the other hand, the total norisoprenoids compounds was higher in Arinarnoa with more than double the concentration of the other varieties.

The benzenoids and volatile phenols was the quantitative more important group of aromatic precursors compounds. Interesting, for the high anthocyanin content variety Aspirant Bouschet, the sum of benzenoids and volatile phenols compounds results in around $870 \mu \mathrm{g} / \mathrm{kg}$, the highest value determined for the varieties analyzed. The Arinarnoa and Ancellota with $780 \mu \mathrm{g} / \mathrm{kg}$ and $760 \mu \mathrm{g} / \mathrm{kg}$ was the other two variety with highest values for these groups of compounds.

In conclusion, from these results, we infer that these less frequent red grape varieties cultivated have enological potential, which can easily be transferred to the wine by means of suitable winemaking practices. On the other hand, the data presented can be evaluated for the use of these varieties in blend wines with more planted varieties in the country.

\section{Referencias}

[1] P. This, T. Lacombe, M.R. Thomas, Trends Genet. 22, 511 (2006)

[2] M. Garcia-Marino, J.C. Rivas-Gonzalo, E. Ibáñez, C. Garcia-Moreno, Anal. Chim. Acta 563, 44 (2006) 
[3] E. Boido, M. Garcia-Marino, E. Dellacassa, F. Carrau, J.C. Rivas-Gonzalo, M.T. Escribano-Bailón, Aust. J. Grape Wine Res. 17, 383 (2011)

[4] T. Castia, M.A. Franco, F. Mattivi, G. Muggiolu, G. Sferlazzo, G. Versini, Sci. Aliment. 12, 239 (1992)
[5] C. Barnaba, E. Dellacassa, G. Nicolini, M. Giacomelli, T.R. Villegas, T. Nardin, R. Larcher, Food Res. Int. 98, 20 (2017)

[6] E. Boido, L. Fariña, F. Carrau, E. Dellacassa, D. Cozzolino, Food Anal. Methods 6, 100 (2013) 